\title{
Fundamentos genéticos del comienzo de la vida humana
}

\author{
Dr. Ricardo Cruz-Coke*
}

Durante esta última década, la civilización de Occidente ha comenzado a sufrir una grave crisis de conciencia con ocasión de la aprobación legal y política del aborto $y$ feticidio del ser humano. Se ha plateado pues el problema de que existen derechos inalienable del feto para vivir: los que hoy llamamos derechos del niño antes de nacer.

Este problema es vital y esencial en el desarroIlo de la cultura de nuestra civilización. Es el problema de mayor prioridad e importancia entre todos los de naturaleza moral, legal, científico y filosófico que abruman nuestra vida intelectual y espiritual.

Es difícil tomar partido en la gran controversia que se ha abierto en torno a este problema, sin considerar la profundidad de los propios conceptos éticos y humanísticos que todo médico tiene enraizado en su educación y formación profesional.

Sin embargo creemos que es posible hacer una contribución objetiva y científica al esclarecimiento de muchos aspectos de este problema que han sido distorsionados y tergiversados. Me refiero a la discrepancia que existe en estimar el momento en que comienza la vida humana y desde cuándo existe realmente la persona humana cuyos derechos a la vida queremos defender y preservar.

Abordaremos en esta oportunidad el estudio de los fundamentos genéticos del comienzo de la vida del ser humano. Ordenaremos nuestra exposición en fa siguiente secuencia:

1) Definición de Concepción. Fecundación y Feto.

2) El Proceso de la Fecundación

3) La Vida Fetal

4) Evidencias del Comienzo de la Vida en la Fecundación.

5) Conclusión

\section{DEFINICION DE CONCEPCION, FECUNDACION Y FETO}

La idea que la concepción es un acto que procrea a un ser es muy antigua y está claramente definida en los Diccionarios de la Academia de la Lengua en el siglo XVIII. En 1868 se definia el vocablo Concepción como: "Unión de los materiales suministrados por ambos sexos en el acto generativo para la procreación de un nuevo ser". El fruto de esta concepción se llama Feto, y su defimición en los diccionarios en 1790 y 1803 e. : "Lo que la hembra de cualquier animal concibe y tiene en su vientre". En esa época se considera que el verbo Concebir es: "Hacerse preñada la hembra".

Las definiciones anglosajonas más recientes (W'ebster) definen la concepción en tres acepciones biológicas: 1$)$ Acto de estar preñada 2) Formación de un zigoto viable y 3) Estado de ser concebido.

Por tanto la idea no biolúgica de la concepción de un ser humano está directa e inequivocadamente relacionada con el comienzo de su vida. La concepción es un acto. un momento, donde se efectúa un proceso binlógico denominado fecundación. La fecundación se define como la fertilización de un óvulo mediante un espermio. Es decir la unión de un gameto masculino con otro femenino.

E] mecanismo de la fecundación en la especie humana sólo fue demostrado por Hertwig en 1875. Desde entonces comenzaron a desarrollarse conceptos y definiciones biológicas como ser: gametos. células, zigotos. genes. cromosomas, Después de un siglo de progreso de los descubrimientos científicos biológicos es posible establecer claramente la secuencia del proceso de trasmisión de la vida de una generación a otra y la procreación de un nuevo ser humano.

\section{EL PROCESO DE LA FECUVDACION}

La fecundación es un corto periodo (unas $24 \mathrm{hrs}$.) del
-Profesor de Medicina y Trenética, Facultad de Medicina, Sede Norte. Universidad de Chile. 
proceso de reproducción durante el cual se origina la vida de un ser. Su estudio debe abordarse en varios niveles biológicos: molecular, genético, celular. endocrino y poblacional. Trataremos de resumir la complejidad de este estudio.

En la especie humana la vida se trasmite mediante un mecanismo de reproducción sexual el cual depende de la fusión de dos células, llamadas gametos; uno masculino, el espermio y otro femenino: el óvulo. El gameto masculino fecunda al ovulo femenjno. Como resultado se forma una nueva célula; e] zigoto. El zigoto es pues una célula formada por dos gametos.

Los gametos y el zigoto están definidos genéticamente por el número de cromosomas que acarrean. Cada gameto tiene 23 cromosomas y el zigoto 46. Los cromosomas están en pares, de modo que el gameto contiene sólo un juego de pares: es una célula haploide. El zigoto al tener los dos juegos campletos de pares es diploide.

EI zigoto es pues una célula primordial que contiene todos los cromosomas del ser humano, y por consiguiente también todos sus genes.

Ahora bien, los ccomosomas trasportan los ge. nes. Estos están ubicados en lugares precisos denominados Incus a sitio o lugar. Hay un par de genes en el par de cromosomas. Si un gen $A$ viene en un gameto y el gen $B$ viene del otro gameto. al fusionarse para formar el ziggoto, éste lendrá ahora A y B. el par AB y por lo tanto será una célula genéticamente diferente de los gametos progenitures. El zigoto tendrá una fórmula o constitución genétíca llamada genotipo, en este caso AB.

Es muy importante recalcar la idea que la formación de un genotipo $\mathrm{AB}$ se hace mediante dos procesos matemáticos: una sumatoria de $A+B=A B$ y de una multiplicatoria $A \times B=A B$.

La sumatoria es la adición física de las masas nucleares del espermio y la citológica del ovulo y la conjunción de sus cromosomas.

La multiplicatoria es la interconexión teórica de las probabilidades de existir de los genes en la combinatoria del azar. El determinismo de la estructura final del genotipo $\mathrm{AB}$, en vez de un genotipo $\mathrm{AC}$, se define inequivocadamente en la fecundación.

La teoría genética por tanto sostiene que el genotipo del individuo ya está formado definitivamente en el momento de la concepción, o lo que es lo mismo en el acto de la fecundación cuando se origina físicamente y probabilisticamente el zigoto, que es la célula primordial del ser humano.
Ahora bien. la fecundación es un proceso de trasmisión de la vida de una generación a otra. No hay creación. Hay una copia de moldes genéticos. Para ello es importante comprender el mecanismo molecular de trasmisión de la vida. En efecto, cuando estudiamos el problema de la división celular a nivel molecular podemos constatar que el proceso de trasmisión genética del gameto al zigoto no es un transporte material de moléculas, sino que es un proceso de copia con moldes.

Las diversas moléculas que constituyen los genes y los cromosomas se duplican mediante un procesı en el cual cada banda o hebra del ácido nucleico DNA sirve de molde para formar una banda complementaria. El mecanismo de copia es semi-conservador porque el DNA resultante está formado por una banda paterna y otra banda nueva que es una reproducción exacta de la original. Por consiguiente este mecanismo de duplicación semi-conservador, asegura que cada zigoto contiene una estructura genética física nueva y original. La doble hélice del DNA no se reproduce como un todo entero, sino que por mitad original. El nuevo DNA del zigoto tiene pues una identidad propia cronológica y generacional.

Es un nuevo ser biologico. Es único en la historia de la especie. Y todo este determinismo e identificación del individuo humano ocurre en el instante de la fecundación, de la concepción, cuando $A+B$ es igual a $A B$ y cuando $A \times B$ es también igual a $\mathbf{A B}$.

Ahora podemos empezar a comprender en su contexto como se inicia la vida humana y se desarroIla en forma de feto. Lejeune nos ha dado un magnífico ejemplo. La célula primordial; el zigoto es comparable a un magnetofón con su cinta magnética. La banda de registro de la cinta es el DNA. En esta banda magnética o molécula de DNA están inscritas una serie de señales que detallan las características del individuo: son el genotipo. Al ponerse en marcha el mecanismo del magnetofón, la obra humana. la vida humana es vivida estrictamente conforme a su propio programa (a su genotipo). Todo se desarrolla en base a la información primitiva grabada en el DNA desde el momento de formación del zigoto.

De acuerdo a un estricto análisis biológico determinista, el comienzo de la vida humana se remonta exactamente a la fecundación y toda la existencia humana desde las primeras divisiones celulares del zigoto hasta la extrema vejez. no es más que un desarrollo y ampliación del tema primitivo.

Naturalmente que este formato o molde genético del individuo permite una amplia libertad individual para actual en la vida al amparo del libre albe- 
drío. El determinismo genético está limitado a lo estrictamente necesario para desarrollar y mantener la individualidad e identidad de cada ser humano.

\section{LA VIDA FETAL}

El ser humano recibe el nombre genético de Feto durante toda la vida intrauterina. pero como atraviesa por diversos períodos de desarrollo recibe otros tantos nombres. Pese a que el proceso de desarrullo fetal es gradual. por motivos técnicos se acostumbra a dividir la vida fetal en varias etapas.

La primera etapa de una semana es el periodo de preimplantación y el feto se llama blastocito. Al implantarse en la pared uterina, el blastocito recibe el nombre de embrión. El embrión genéricamente se define como un germen de ser vivo. Embrión es un feto, de la raíz griega $\mathrm{Eu} \longrightarrow$ dentro de bryos-pulular o reproducción rápida.

En esta segunda etapa de unos 2 meses el embrión forma los órganos del feto, al cabo de 203 meses el ser humano tiene ya una forma humana y mide alrededor de tres centímetros. Eọte embrión ya es llamado simplemente feto, y comienza una tercera etapa que terminará a los 5 meses.

La cuarta etapa de desarrollo fetal comienza alrededor de los 5 meses. El feto ya es viable; es decir puede vivir fuera del útero. Hay algunos fetos abortados que han vjvido sólo con cuatro meses para morir como mortinatos. Con esta etapa viable el feto completa su evolución hasta el nacimiento entre los 7 y 10 meses.

Durante la vida intrauterina el feto va perfeccionando y desarrollando muchas complejidades genéticas. Se van formando nuevas proteinas y estrucluras vitales. El ser humano está en proceso de fabricación a partir del molde original concebido en la fecundación cuando se forma el zigoto, o célula primordial.

Así. muchos genotipos se modifican y se desarrollan nuevas molécılas. El ejemplo de las moléculas de Hemoglubina es clásico. Las cadenas B de la Hemoglobina se forman después del nacimiento. Solamente al cabo de 3 meses de nacido, esto es un año después de ser concebido el ser bumano llega a tener el genotipo de las Hemoglobinas adultas.

Pero todo este proceso de cambio y transformación es la ampliación del tema primitivo impreso en los genotipos del zigoto.

Es evidente que no se puede adscribir a ninguna de estas etapas del desarrollo fetal el comienzo de la vida humana. El momento de la implantación, al cabo de una semana ha sido considerado por algunos comı el momento inicial, aduciendo que se establece en ese momento físicamente el binomio madrehijo con todas las relaciones endocrinas e inmunológicas. Pero ya vimos que éste es un momento del desarrollo de un tema grabado en el genotipo. En efecto. si se tratara de la implementación de gemelos idénticos. los dos blastocitos se implantarían a distintas horas con sus individualidades y genotipos ya formados a distintos tiempos. El mecanismo de separación es anterior a la implantación. Es evidente que la vida de los gemelos idénticos no comienza en la implantación. Ha comenzado en la primera división celular del zigoto en la fecundación.

La determinación del momento de la iniciación de la vida por la viabilidad del feto es otro criterio arbitrario. Hay algunos productos de la concepción que son abortados a los cuatro meses y logran vivir unas semanas. Sin embargo han sido abortados legalmente. Se produce así un conflicto legal, criminal absurdo. pues no hay límite preciso para el tiempode viabilidad. en que el feto puede vivir fuera del útero. No tiene base científica tal límite legal del origen del ser humano.

\section{EYIDENCIAS DEL COMIENZO DE LA VIDA EN LA FECUNDACION}

Las evidencias naturales y experimentales que la vida humana es determinada en su identidad y unidad original en el momento de la fecundación están dadas por:
a) existencia de gemelos idénticos
b) existencia de gemelos imperfectos
c) existencia de hemafroditas

a) Los gemelos idénticos

Los gemelos idénticos surgen de un solo óvulo fecundado. El mecanismo de división es muy precoz. contemporáneo a la primera división celular. Se forman dos individuos diferentes pero con un patrimonio genético común. El genotipo de ambos gemelos es idéntico, de ahí su nombre. Antes de la implantaciôn ya están definidas las individualidades.

b) Los gemelos imperfectos.

Se han descrito casos extremos patológicos de formación de gemelos idénticos, uno afectado con mongolismo y el otro sano. La explicación de eate fenómeno es que la aberración cromosómica se produjo en las primeras segmentaciones o divisiones de los blastocitos. Por tanto se conforman la precoz determinación de la individualidad de cada gemelo. 
Otro ejemplo es la formación de gemelos imperfectos por pérdida de la transmisión del cromosoma Y. A partir de un óvulo fecundado XY, masculino, al dividirse en dos. uno de los gemelos no recibe el cromosuma Y. Se forma un gemelo con cromosoma $X$. por lo cual el gemelo es mujer, pero como le falta otro $\mathrm{X}$ no puede desarrollar feminidad. Se forman asi dos gemelos con individualidad separada de sexos.

Eslas determinaciones de la individualidad de cada gemelo se hacen en el período de la fecundación, mucho antes de la implantación.

c) Los hemafruditas son sujetos portadores de células masculinas $\mathrm{XY}$ y femeninas $\mathrm{XX}$ y por tanto tienen atributos simultáneos de varón y mujer. Esto resulta de la fecundación simultánea reciproca de dos células femeninas. el óvulo y el corpúsculo polar voluminoso. Se forman individues que sen mosaicos $\mathrm{XX} / \mathrm{XY}$.

También estos tipos raros de seres humanos son originados en el período de la fecundación.

\section{CONCLUSION}

Del estado actual de los conocimientos científicos de la Biología y la Genética es posible llegar a las siguientes conclusiones sobre el comienzo de la vida humana:

1) El ser humano es una individualidad genética única en la historia de la especie humana. Es un ser único, no reproducible. Su identidad biológica se determina en el comienzo de su vida.

2) La vida de un ser humano tiene un comienzo y un final en el tiempo. Su comienzo es el momento de la concepción y su fin la muerte dentro o fuera del útero de su madre.

3) El ser humano se forma genéticamente a nivel molecular, citológico y probabilístico al fusio- narse los dos gameros masculino y femenino y estructurar un zigoto que es la célula primordial que contiene todos los genotipos originales a partir de los cuales se desarrollará la vida del nuevo ser. Este proceso que se desarrolla en pocas horas se llama fecundación. es el sustrato biológioo de la concepción. La vida comienza en la fecundación.

4) Con la fecundación del óvulo y la formación del zigoto se inicja un nuevo ser que es distinto a sus progenitores, y tiene la potencialidad e individualidad para desarrollarse por sí mismo.

5) El producto de la concepción es el feto. el cual durante la vida intrauterina pasa por sucesivas etapas de desarrollo que lo van adaptando a los ecosistemas materno para completar la fabricación de un infante capaz de ser viable. Ninguna de estas etapas puede ser considerada como comienzo de su vida. la que ya comenzó en la fecundación. Al completar nuestra revisión del problema de la determinación genética del comienzo de la vida humana, podemos afirmar que la genética contribuye en forma decisiva a fundamentar los derechos del feto a vivir desde el moment $s$ mismo de la concepción. En efecto. así lo han reconocido recientemente tanto los fisiólogos que estudian la fecundación "in vitro". como el documento pontificio del Vaticano sobre el aborto.

El Padre Juan Gregorio Mendel, fundador de la Genética. ha venido a sumarse al juramento de Hipócrates. padre de la Medicina y a la doctrina predicada por Cristo, para defender en forma absoluta el derecho a la vida, del niño por nacer.

De este modo. apoyados por la gran tradición hipocrática. cristiana y mendeliana, nusotros, los médicos genetistas. responsablemente y seguros que estamos defendiendo las vidas de millones de niños que nacerán en los tiempos venideros. nos atrevemos a repetir el lamado del gran poeta cuando exclamó "Sube a nacer conmign, hermano". 